\title{
Populismo, mídia educacional e escolas em tempos de crise
}

\author{
Populism, educational media and schools in times of crisis
}

Christoph Kohl ${ }^{2}$

\section{RESUMO}

Em vários países europeus e no exterior, partidos e movimentos políticos populistas - tanto de esquerda quanto de direita - experienciaram uma popularidade crescente nos últimos anos. Estes desenvolvimentos são devidos a uma incerteza pronunciada entre as partes vitais das populações, devido a complexidades crescentes nas sociedades e à aceleração de mudanças e desafios na vida diária, incluindo o setor de educação. Muitos desses movimentos e partidos têm a reputação de usar uma retórica nacionalista exclusiva, retratando-se como supostamente "verdadeiros" defensores dos interesses operários e da classe média. Além disso, eles pretendem representar a voz do "povo" mais autêntica do que "as elites" fazer, desafiando as culturas de memória estabelecidos e parcialmente tentativa de substituí-los por versões supostamente mais autênticas do passado. Usando exemplos de diferentes países, o presente trabalho pretende examinar as formas em que eles estão sendo discutidos no setor de educação e livros escolares. O documento gostaria de discutir, como e em que medida nos contextos póscoloniais em outros lugares. Gostaríamos de discutir como os discursos hegemônicos são contestados pelos populistas, caso e em que medida eles tentam influenciar e reconstruir a identidade, a memória e a história, e as estruturas do escolar através da educação contra tradições anteriores ou prevalecentes e como eles - para esse propósito - influenciam a produção de mídia educacional.

Palavras-chave: Populismo. Mídia educacional. Livros escolares. Identidade. Memória. História.

\section{ABSTRACT}

In many countries in Europe and abroad, populist political parties and movements - both left and right - have experienced an increasing popularity in recent years. These developments are due to a sharp uncertainty among the vital shares of populations, due to increasing complexities in societies and to the acceleration of changes and challenges in daily life, including the educational sector. Many movements and parties have the reputation to use a rhetoric that is exclusive nationalist, portraying themselves as the supposedly "real" defenders of the workers and middle class' interests. Also, they intend to represent the voice of the "people" more authentically than "the elite" does, defying the establishes cultures of memory and partially traying to substitute them for supposedly more authentic versions of the past. Using examples from different countries, this work intends to examine the ways in what they are being discussed in the educational sector and school books. The document would like to discuss how and the extend

\footnotetext{
1 Texto apresentado III Congresso Ibero-Americano de Educação Histórica, o XI Seminário Internacional de Educação Histórica e o XV Encontro do Laboratório de Pesquisa em Educação Histórica (LAPEDUH-UFPR), Curitiba, PR, Brasil, 14-17 de novembro de 2018.

2 Instituto Georg Eckert para a Pesquisa Internacional de Livros Didáticos (GEI), Braunschweig, Alemanha.
} 
of it in the post-colonial contexts in other places. We would like to discuss how the hegemonic speeches are contested by the populists, if and the extend they tried to influence and reconstruct the identity, the memory and the history, and the scholar structures through the education against previous or prevailing traditions and how they - for this purpose - influence the production of educational media.

Keywords: Populism. Educational media. School books. Identity. Memory. History.

\section{Introdução}

Em vários países ao redor do mundo movimentos políticos populistas têm desfrutado de uma crescente popularidade nos últimos anos. Enquanto fingem representar a voz do "povo" mais autenticamente do que "as elites", ou seja os partidos e políticos "estabelecidos", eles também desafiam os sistemas de educação e mídia educacional, notavelmente os livros escolares e currículos.

A seguir, argumentamos que os populistas, em muitos casos, traduzem estratégias de um ambiente para outro, resultando em muitas semelhanças de abordagens entre vários países. Estratégias bem-sucedidas são copiadas e traduzidas em contextos locais, quer dizer, são vernacularizadas (MERRY, 2006). Existem fundamentos comuns em vários países, como a convicção de que uma elite supostamente corrupta e moralmente falida contribuiu para uma distorção e afastamento do que é enquadrado como a realidade das pessoas no setor educacional e na mídia educacional. Enquanto isso, o sucesso dos populistas em relação à tentativa de disseminação de narrativas e memórias históricas alternativas e supostamente mais autênticas na mídia educacional está intimamente relacionado às práticas de ensino nas escolas.

Durante anos, se não décadas, especialistas didáticos exigiram mudar o foco da história e da educação em ciências sociais de uma ênfase na coerência histórica e continuidade para abordagens que colocam o ensino de habilidades metodológicas - como a contextualização de eventos passados e a análise de multiperspectividade - no centro. No entanto, embora essas demandas tenham caído em terreno fértil, levando algumas administrações escolares a incorporarem tais habilidades metodológicas em seus currículos e na formação de professores, muitos aprendentes ainda têm pouca ou nenhuma competência para analisar criticamente o passado. Isso joga nas mãos de populistas que, de fato, visam eliminar qualquer forma de poliperspectividade e contingência. Em vez disso, eles desejam um retorno a mensagens inequívocas e "verdades" autênticas, deixando para trás análise crítica, multiperspectividade e polifonia. Além disso, no entanto, atores populistas são também ativos 
em mais outros setores educacionais, como vou mostrar. Antes, gostaria especificar o conceito de populismo.

\section{O que é populismo?}

Em primeiro lugar, é importante distinguir entre o uso do termo "populismo" nos debates públicos e na academia. Em outras palavras, as perspectivas analíticas precisam ser separadas das visões internas dos olhos dos atores. Embora nenhuma definição consensual tenha surgido até agora, ao longo dos últimos anos, no entanto, as abordagens ideacionais concebendo o populismo como um conjunto de ideias - ganharam influência e foram empregadas com sucesso em estudos comparativos (por exemplo, Hawkins, Riding e Mudde (2012); cf. Mudde e Rovira Kaltwasser (2013, p. 150) e Mudde (2017, p. 28)). De acordo com essa abordagem, o populismo pode ser definido como, segundo Cas Mudde (2004, p. 543)

\footnotetext{
Uma ideologia que considera a sociedade em última instância separada em dois grupos homogêneos e antagônicos, 'o povo puro' versus 'a elite corrupta', e que argumenta que a política deveria ser uma expressão da volonté générale (vontade geral) do povo." [ênfase no original, tradução do inglês].
}

Mais precisamente, o populismo pode ser assim caracterizado como uma ideologia "fina", que é limitada em sua ambição e escopo e, portanto, não oferece argumentos complexos como ideologias "completas" (como, por exemplo, o socialismo, liberalismo ou fascismo), mas oscila com o vento. O populismo é baseado em uma distinção moral entre as pessoas "autênticas", "puras", "honestas" de um lado e uma elite "corrupta", "patológica" e "desonesta" que trai a primeira de outro, sendo ambas vistas como comunidades homogêneas e virtuosas. O povo é, portanto, atribuído a uma "vontade geral" (MUDDE; KALTWASSER, 2013, p. 150-151; MÜLLER, 2016, p. 3-4, 20, 41; MUDDE, 2017, p. 30-34). Em outras palavras, os populistas rejeitam a evidência empírica de que as pessoas de uma determinada sociedade são divididas por clivagens que separam os defensores dos adversários de certas questões políticas (LIPSET; ROKKAN, 1967; MÜLLER, 2016, p. 3-4). Isto implica que os populistas são anti-pluralistas. Resumindo, como escreve Jan-Werner Müller (2016, p. 101),

\footnotetext{
Eles afirmam que eles e eles só representam o povo. Todos os outros concorrentes políticos são essencialmente ilegítimos, e quem não os apoia não faz parte do povo. Quando na oposição, os populistas insistirão necessariamente que as elites são imorais, enquanto o povo é uma entidade moral e homogênea, cuja vontade não pode errar [tradução do inglês].
}

Apesar de suas alegações de que apenas eles representam "o povo", muitos populistas demonstram implícita- ou explicitamente que são influenciados por tendências autoritárias 
(MUDDE; KALTWASSER, 2013, p. 506; MÜLLER, 2016, p. 4, 58). Atores populistas não apenas constroem um antagonismo vertical entre "o povo" e "a elite", mas também um antagonismo horizontal entre "insiders" e "outsiders" (LEWANDOWSKY, 2017, p. 6). Ao mesmo tempo, os populistas se comportam e se retratam discursivamente como vítimas (MÜLLER, 2016, p. 42).

\section{Abordagens Populistas em Relação à Educação}

A seguir, identificamos uma série de campos educacionais nos quais os populistas promovem ou exigem mudanças. Os partidos e movimentos políticos mencionados representam o que é usualmente descrito como o político de direita e correspondem à nossa compreensão ideacional do populismo, com base na definição apresentada acima. Os exemplos usados vêm em muitos casos dos países do Norte Global e, em alguns casos, representam declarações de intenção de serem reivindicadas a serem implementadas assim que os respectivos partidos populistas chegam ao poder. No entanto, vamos descobrir certos paralelos com o caso do Brasil. Um olhar comparativo revela que os populistas têm perseguido uma série de estratégias, algumas traduzidas através das fronteiras nacionais que estão parcialmente entrelaçadas. No entanto, embora haja muitos motivos comuns, os objetivos e as justificativas podem diferir de país para país:

(1) Fazendo a voz dos povos ouvida, combatendo a alegada "doutrinação política". Tanto na Alemanha quanto na Áustria, os partidos populistas de direita AfD (Alternativa para a Alemanha) e FPÖ (Partido da Liberdade da Áustria), respectivamente, iniciaram iniciativas para combater o que eles chamam de "doutrinação política" (KLOVERT, 2018) de alunos por professores. No início de 2017, o FPÖ austríaco apresentou um website "escola não partidária", onde os usuários podiam denunciar anonimamente declarações políticas de professores que, por exemplo, associavam o partido político ao extremismo de direita (KONTRAST REDAKTION, 2017). De acordo com o FPÖ, "lapsos verbais" e outras violações de "objetividade" pelos professores devem ser relatados anonimamente, independentemente de alinhamentos políticos. Após pesados protestos iniciais de outros partidos e sindicatos de professores por intimidação e denúncia, entre outros, o logotipo do partido desapareceu do site, o FPÖ presumivelmente tentando retratar o projeto como politicamente apartidário. Mesmo antes, as violações podiam ser denunciadas às autoridades estaduais de educação, que, no entanto, falharam na maioria dos casos devido à falta de provas (PFANDLER, 2017; WEITER..., 2017). O site ficou offline logo após, oficialmente devido a trabalhos de manutenção (FPÖ FAILS, 2018). 
Um ano mais tarde, a AfD alemã seguiu em meados de 2018. Políticos em vários estados federais anunciaram a planejaram a criação de plataformas interactivas (que o partido minimizou como "caixa de queixas", ou "caixa de sugestões"), onde professores, pais e alunos poderiam relatar incidentes anti-AfD. De acordo com um político AfD, a "educação política" foi muitas vezes confundida com a "doutrinação política", o que violou os "princípio da neutralidade". No entanto, o principal sindicato dos professores referiu-se ao chamado Consenso de Beutelsbach, concluido em 1976 (SCHLINK, 2018; MUNZINGER, 2018). De acordo com este acordo, "não é permitido para pegar alunos despreparados ou surpresa por qualquer meio - por uma questão de transmitir opiniões desejável e para impedi-los de uma formação de julgamento independente'. É precisamente neste ponto que faz a linha divisória funciona entre educação política e doutrinação. Doutrinação é incompatível com o papel de um professor em uma sociedade democrática e o objetivo universalmente aceite de tornar os alunos capazes de julgamento independente" (LPB, [201-]). Assim, a AfD foi acusado de intencionalmente confundir uma doutrinação, ilegítimo manipuladora com uma disputa aberta, livre e controversa (SCHLINK, 2018). Semelhante a Áustria, a AfD tentou retratar-se como vítima de uma conspiração política (KLOVERT, 2018; MUNZINGER, 2018), com a intenção de suprimir discussões críticas e pluralistas. Como na Áustria, os sindicatos de professores e autoridades escolares condenaram o plano enquanto a AfD se sentia incompreendido (AFP, 2018; NDR, 2018). A AfD percebe os professores e outros representantes do Estado cada vez mais como "colaboradores" e fantasia sobre a sua "eliminação", demonstrando uma radicalização também em termos lingüísticos. Reclamações disciplinares são um meio com o qual a AfD tem tentado silenciar professores "doutrinados", que acusam de "pensar de uma maneira socialista" e de defender uma "re-educação ideológica" (NEWS4TEACHERS, 2018a, 2018b). São, de fato, práticas que lembram à iniciativa "Escola sem Partido" (ESP) no Brasil.

(2) Oposição à Educação Sexual Escolar e Não-Conformidade de Gênero. Em colaboração com atores cristãos-fundamentalistas, entre eles membros da AfD alemã, populistas na Alemanha referem-se ao "senso comum" e tentam desacreditar as abordagens como a da integração de gênero. Também, argumentam com argumentos falsos e homofóbicos contra a educação sexual escolar como "sexualização precoce" que supostamente viola a "soberania da educação dos pais" e supostamente abre caminhos para uma "juventude pornografada" (HOFFMANN, 2017). Outros exemplos são, entre outros, o Brasil e os Estados Unidos (PAIVA; SILVA, 2015). Particularmente, a vitória eleitoral de Donald Trump sinalizou o início de um retrocesso nas proteções antidiscriminatórias e robustas para pluralismo, era exigido tempo igual nas escolas tanto para a teoria evolucionista 
quanto para as abordagens criacionistas. Em 1999, o estado de Kansas decidiu remover qualquer referência à evolução do currículo, estabelecendo assim o exemplo para outros estados. A autocensura entre as editoras de livros didáticos foi um efeito-chave, pois removeram conteúdo controverso. Pedra angular de muitos evangélicos populistas e autoritários é a crença na degeneração social devido a um suposto ataque contra os valores cristãos e o plano de Deus - como incorporado pelo movimento LGBTI e pela educação sexual escolar, entre outros - impulsionado pelas elites "liberais". Eles acreditam firmemente em uma história objetiva "verdadeira" (dizem: "queremos nossa história de volta"). E eles percebem as descobertas científicas, a heterogeneidade e o pluralismo em geral como uma ameaça.

Semelhante a outros movimentos populistas, eles se vêem como vítimas de uma política de alheamento e silenciamento e se consideram "verdadeiros americanos". Seu conservadorismo moral está associado à crença em mercados livres e empresas privadas (APPLE, 2001). Nos últimos anos, os atores criacionistas adaptaram sua estratégia às normas constitucionais que proíbem "um estabelecimento de religião". Em vez disso, eles estão promovendo leis de "liberdade acadêmica" que foram promulgadas em vários estados na última década. Assim, em vez de mencionar termos controversos como "criacionismo" e "desenho inteligente", eles pretendem defender o pensamento crítico e o pluralismo. Com a inauguração da administração Trump em 2017, os movimentos religioso-populistas ganharam força: a secretária de educação Betsy de Vos - que uma vez qualificou sua abordagem educacional como uma contribuição para "avançar o reino de Deus" (GLINSKIS, 2017) - , vice-presidente Mike Penn e Jeff Sessions, até há pouco tempo procurador-geral dos Estados Unidos, identificaram-se como proponentes de uma agenda cristã e populista (GLINSKIS, 2017; HABERMAN, 2017). A mistura de uma crença no capitalismo livre do Estado e sem restrições sob os auspícios religiosos também afeta outro grupo de arenas populacionais de educação, isto é, a estruturação básica do sistema escolar.

(3) Reestruturação de Escolaridade e Sistemas Educacionais. Tanto nos Estados Unidos como no Brasil, discursos políticos populistas anti-factuais têm exigido os cortes de gastos, a flexibilização, a ênfase em "habilidades" e "competências" e "escolha de escola" desde que os governos dos presidentes Michel Temer e Donald Trump tomaram escritório. Dessa forma, eles buscam tacitamente reforçar as divisões sociais e deslegitimar medidas de ação afirmativa (MACEDO, 2017; DENNIS, 2017). Nos Estados Unidos, o movimento de escolha livre da escola já é ativo por décadas, mas encontrou defensores proeminentes na administração de Trump, especialmente incorporada pela secretária de educação Betsy de Vos. Já durante seu mandato como governador de Indiana, o atual vice-presidente Mike Pence reforçou os programas de cupons que apoiam a transferência de alunos de escolas 
públicas para escolas privadas, muitos deles religiosos. Considerando que esta privatização se provou cara e como se mostraram efeitos negativos no desempenho e realizações dos aprendentes, estes programas de fato apóiam as escolas religiosas. Eles não precisam atender aos requisitos exigidos pelas escolas públicas, como o respeito ao pluralismo de gênero, as medidas antidiscriminatórias e a neutralidade religiosa (WEAVER, 2018). Da mesma forma, a política educacional da Suécia experimentou uma tendência de competição entre escolas e mais eficiência a partir dos anos 90 . No entanto, as condições de fato se deterioraram à medida que os níveis de desempenho caíram e a desigualdade e a exclusão aumentaram (BEACH, 2017). Na mesma linha, a Reunião Nacional da França, anteriormente conhecido como Frente Nacional, criticou os altos gastos no atual sistema educacional, que pelo menos em documentos favorece a integração e segue uma abordagem igualitária. Em vez disso, a Reunião Nacional argumenta contra qualquer tipo de discriminação positiva, isto é, a ação afirmativa, exigindo maior concorrência e procedimentos de seleção baseados no mérito. Ao mesmo tempo, a "autoridade e respeito do professor", como dizem, deve ser restabelecida. A educação em geral deve ser (re-)centralizada (HOUEL, 2016; JARRAUD, 2017). Mais importante, no entanto, a Reunião Nacional pretende focar a educação básica em "disciplinas centrais", que é francês - a metade das horas deve ser dedicada aos cursos de francês - , história e matemática, com o objetivo de não apenas fortalecer a identidade nacional, mas também orientar os alunos principalmente para a formação profissional em detrimento dos estudos universitários. De acordo com a Reunião Nacional, os cursos de línguas estrangeiras para migrantes e seus descendentes devem ser abolidos e os cursos escolares para estudantes estrangeiros devem ser cobrados (HOUEL, 2016; ZEROUALA, 2017). Assim, todas as conceções que combinam as vertentes conservadora e neoliberal em graus variados prevalecem entre os políticos populistas dos referidos países. A hostilidade sutil a novas abordagens pedagógicas e visões de mundo anticientíficas tácitas também desempenham um papel na seguinte dimensão.

(4) Conhecimento Sujeito em vez de Conhecimento Metodológico. Com base em premissas ideológicas, governos conservadores e populistas iniciaram políticas que levaram a Suécia a abandonar a unificação após 2008. Mais especificamente, com referência aos argumentos do "senso comum", a política populista buscou reajustar a formação de professores, que deveria se concentrar no conhecimento de sujeito em vez que na teoria educacional e didática - apesar do fato de os pesquisadores terem demonstrado que a formação de professores já era muito conservadora $(\mathrm{BEACH}, 2017)$. Da mesma forma, a Reunião Nacional francês exigiu que a educação escolar fosse "menos criativa", pois os 
alunos não eram "cobaias", seu líder Marine Le Pen pedindo o fim de qualquer reforma e experimentos. Em vez disso, a educação deve ser mais realista e aplicada (HOUEL, 2016).

(5) Novos Currículos e Conteúdo de Livros Didáticos. A política populista de direita muitas vezes se concentra em uma reforma dos currículos escolares e do conteúdo dos livros escolares, seguindo uma abordagem conservadora que tende a "reescrever" o passado de maneira nacionalista, marginalizando abordagens críticas, didáticas, multiperspectividade e história a partir de baixo. Na Polônia, por exemplo, o governo eleito em 2015 impôs uma profunda reforma educacional. Assim, a história militar e os heróis políticos e religiosos nacionais são trazidos à tona, enquanto o papel da história social diminui (SAWICKA; SKIBICKI, 2017). De forma semelhante, a política populista húngara removeu do currículo as personalidades que não se encaixavam na abordagem conservadora do governo (PETÖ, 2017), enquanto que, de um modo geral, a revisão da educação e da história supostamente "representa um sentimento de pertença nacional e orgulho, tanto como ressentimento contra os estrangeiros" (BENAZZO, 2017). Visões e intenções semelhantes foram expressas pelos políticos alemães da AfD. Um dos seus principais membros, pertencente à direita, declarou em 2017:

\footnotetext{
Em vez de trazer em contato a geração mais jovem com os grandes benfeitores, os conhecidos filósofos comoventes, os músicos, os engenhosos descobridores e inventores de a quem temos tantas pessoas, talvez [...] mais do que qualquer outra pessoa no mundo [...] e, em vez de colocar nossos alunos nas escolas em contato com essa história, a história da Alemanha se torna mesquinha e ridícula (HÖCKE apud NEWS4TEACHERS, 2018b) [tradução do alemão].
}

Na Índia, o partido populista conservador Bharatiya Janata Party (BJP) ganhou as eleições parlamentares e formou o governo liderado pelo primeiro-ministro Narendra Modi em 2014. O governo do BJP enfatiza fortemente a religião hindu, visando à marginalização dos muçulmanos nas representações históricas. De acordo com uma leitura populista da história, a política era pura, desde que dominada pelas elites religiosas e políticas. Seguindo essa interpretação elitista, a política só se tornou corrupta quando políticos de baixa casta foram incorporados à política sob o governo do Partido Congresso Nacional Indiano, de esquerda e pró-inclusão. Embora esse discurso elitista realmente traga a retórica populista e pró-povo do BJP, eles conseguiram unir seus eleitores empregando uma separação religiosa maniqueísta. Dessa forma, eles construíram uma glorificada versão hindu do passado do país que, ao mesmo tempo, demoniza os governantes muçulmanos dos séculos passados. Embora os livros didáticos das escolas mais antigas continuem a ser usados - incluindo, principalmente, as edições progressivas de 2005, que deram muita ênfase à metodologia - o governo pretende lançar um novo conjunto de livros didáticos de história que reinterpreta o passado 
em seu sentido. No entanto, o governo tem lutado para identificar pesquisadores qualificados para fazê-lo devido ao apoio acadêmico muito limitado.

\section{Conclusão}

Em geral, o foco dos partidos e atores populistas parece ser freqüentemente de interesse nacional; portanto, eles visam a reinterpretar a história de uma forma que segue uma lógica ingroup-outgroup, portanto de exclusão, segregação, anti-gênero, racialização etc. Ou, como colocou o cientista educacional André Epp, os seus"[...] conceitos apresentam uma forte normatividade e tendem a criar estereótipos e generalizações" (EPP, 2017, p. 174). Mais geralmente, os populistas acreditam que

Os indivíduos não devem questionar o conhecimento que acumulam. Eles deveriam aceitá-lo como um dado fato e estão tão reduzidos a um consumidor não-crítico de educação. [...] Afetada pela racionalização econômica, o modo de pensar é reduzido e simplificado (EPP, 2017, p. 171).

Evidências preliminares sugerem que os populistas querem retornar a uma narração coerente da história que deixa pouco ou nenhum espaço para dúvida e análise crítica, multiperspectividade e multivocalidade. Em vez disso, as políticas populistas de educação concentram-se na concentração da história política, nacional e militar e nas histórias heroicas, atribuindo claramente a culpa a atores e grupos específicos. Ao mesmo tempo, a história social com foco em contar o passado a partir de baixo é paralela. Os contextos sociais são inadequadamente representados, enquanto a realidade social é concebida como um fato imutável (EPP, 2017, p. 169). Assim, em outras palavras, os populistas - assim como em outras políticas - tendem a substituir uma história "intelectual" e "elitista" por uma suposta história do "senso comum".

É importante ressaltar que as estratégias do tipo ideal, listadas, perseguidas pelos populistas são traduzidas através das fronteiras nacionais para diferentes contextos de educação do país. Embora o foco das políticas populistas de educação possa variar, os conceitos parecem ser transportados e vernacularizados para contextos sociais, históricos, políticos e culturais específicos de cada país, muitas vezes revertendo a crenças reducionistas neoliberais e referências emocionais ao "senso comum".

Vale a pena, no meu entender, debater como os países diferentes - e em particular o Brasil - poderiam garantir uma educação aberta, integrativa e pluralista para também ganhar os alunos para uma atitude democrático. 


\section{Referências}

AFP - AGENCE FRANCE-PRESSE. Onlinepranger für AfD-kritische Lehrer laut LandtagsJuristen illegal. Münchner Merkur, München, 31 Mai 2018. Disponível em: https://www.merkur.de/politik/onlinepranger-fuer-afd-kritische-lehrer-laut-landtagsjuristenillegal-zr-9913824.html. Acesso em: 11 jun. 2018.

APPLE, Michael Whitman. Bringing the world to God: education and the politics of authoritarian religious populism. Discourse: Studies in the Cultural Politics of Education, London, v. 22, n. 2, p. 149-172, 2001.

$\mathrm{BEACH}$, Dennis. Steering by ideology in (teacher) education: populism and education politics. In: AKBABA, Yalız; JEFFREY, Bob (ed.). The implications of 'New Populism' for education. New Cottage: E\&E Publishing, 2017. p. 65-86.

BENAZZO, Simone. Not all the past needs to be used: features of Fidesz's politics of memory. Journal of Nationalism, Memory \& Language Politics, Berlin, v. 11, n. 2, p. 198-221, 2017.

DENNIS, Barbara. Ethnographer as public scholar in the age of anti-factualist "populism". In: AKBABA, Yalız; JEFFREY, Bob (ed.). The implications of 'New Populism' for education. New Cottage: E\&E Publishing, 2017. p. 53-64.

EPP, André. Educational populism? Reification rhetoric in teacher language. In: AKBABA, Yalız; JEFFREY, Bob (ed.). The implications of 'New Populism' for education. New Cottage: E\&E Publishing, 2017. p. 169-180.

FPÖ FAILS. Parteifreie Schule. [S. I.], 11 Apr. 2018. Disponível em: https://fpoefails.org/2018/04/11/parteifreie-schule/. Acesso em: 31 ago. 2018.

GLINSKIS, Emmalina. Teaching what the "Lord has made": Trump's election may be the second coming for creationism in schools. In: VICE MEDIA LLC. Vice News. New York, 27 May 2017. Disponível em: https://news.vice.com/en_us/article/wjzyp5/trumps-election-maybe-the-second-comingfor-teaching-creationism. Acesso em: 6 set. 2018.

HABERMAN, Clyde. Questioning evolution: the push to change science class. The New York Times, New York, 19 Nov. 2017. Disponível em: https://www.nytimes.com/2017/11/19/us/retro-report-evolution-science.html. Acesso em: 5 set. 2018.

HAWKINS, Kirk; RIDING, Scott; MUDDE, Cas. Measuring populist attitudes. C\&M Working Paper, Mexico City, n. 55, 2012. Disponível em: https://works.bepress.com/cas_mudde/72/. Acesso em: 15 ago. 2018.

HOFFMANN, Markus. School sex education as an object of populist agitation. In: AKBABA, Yalız; JEFFREY, Bob (ed.). The implications of 'New Populism' for education. New Cottage: E\&E Publishing, 2017. p. 143-154.

HOUEL, Jean-Charles. Les projets de Marine Le Pen sur l'éducation: une vision de cauchemar. Mediapart, Paris, 26 sept. 2016. Disponível em: https://blogs.mediapart.fr/jeancharleshouel201/blog/260916/les-projets-de-marine-le-pen-surleducation-une-vision-de-cauchemar. Acesso em: 4 set. 2018. 
JARRAUD, François. Front National: un programme éducatif ni fait, ni à faire. In: ASSOCIATION CIIP. Le Café Pédagogique. Paris, 27 avril 2017. Disponível em: http://www.cafepedagogique.net/LEXPRESSO/Pages/2017/04/27042017Article6362887552 10536308.aspx. Acesso em: 4 set. 2018.

KLOVERT, Heike. Aufsichtsbeschwerde und Onlineplattform: Müssen Lehrer die AfD fürchten? In: SPIEGEL ONLINE GMBH \& CO. KG. Spiegel Online. Hamburg, 12 Juni 2018. Disponível em: http://www.spiegel.de/lebenundlernen/schule/afd-plant-meldeportalegegenlehrer-und-schulen-die-wichtigsten-antworten-a-1232276.html. Acesso em: 12 jun. 2018.

KONTRAST REDAKTION. Wie die FPÖ in Oberösterreich bestimmen will, was Lehrer sagen dürfen. In: SPÖ-PARLAMENTSKLUB. Kontrast.at. Wien, 30 März 2017. Disponível em: https://kontrast.at/wie-die-fpoe-in-oberoesterreich-bestimmen-will-was-lehrer-sagen-duerfen/. Acesso em: 31 ago. 2018.

LEWANDOWSKY, Marcel. Was ist und wie wirkt Rechtspopulismus. Bürger \& Staat, Stuttgart, n. 1, p. 4-11, 2017.

LPB - LANDESZENTRALE FÜR POLITISCHE BILDUNG BADEN-WÜRTTEMBERG. Beutelsbacher Konsens: standard für den politisch-historischen Unterricht an allen Schulen. Stuttgart, [201-]. Disponível em: https://www.lpb-bw.de/beutelsbacher-konsens.html. Acesso em: 31 ago. 2018.

MACEDO, Denise Silva. Education, neoliberal globalization and populism. In: AKBABA, Yalız; JEFFREY, Bob (ed.). The implications of 'New Populism' for education. New Cottage: E\&E Publishing, 2017. p. 101-114.

MERRY, Sally Engle. Transnational human rights and local activism: mapping the middle. American Anthropologist, Arlington. v. 108, n. 1, p. 38-51, 2006.

MUDDE, Cas. Populism: an ideational approach. In: KALTWASSER, Cristóbal Rovira et al. (ed.). Oxford Handbook of Populism. Oxford: Oxford University Press, 2017. p. 27-47.

MUDDE, Cas; KALTWASSER, Cristóbal Rovira. Exclusionary vs. inclusionary populism: comparing contemporary Europe and Latin America. Government and Opposition, London, v. 48, n. 2, p. 147-174, 2013.

MÜLLER, Jan-Werner. What is populism? Philadelphia: University of Pennsylvania, 2016.

MUNZINGER, Paul. Die AfD hat die Schulen für sich entdeckt. Süddeutsche Zeitung, München, 7 Juni 2018. Disponível em: https://www.sueddeutsche.de/bildung/afd-schulenmeinung-1.4006001. Acesso em: 11 jun. 2018.

NDR - NORDDEUTSCHE RUNDFUNK. Schulbehörde: AfD-Aktion fördert Denunziantentum. Hamburg, 212018.2 Sept. 21 em: https://www.ndr.de/nachrichten/hamburg/Schulbehoerde-AfD-Aktion-foerdert-

Denunziantentum,schulbehoerde108.html. Acesso em: 27 set. 2018.

NEWS4TEACHERS. „Endlich wird in Deutschland aufgeräumt“: AfD-Politiker beflügeln "Entsorgungs"-Fantasien gegen parteikritische Lehrer. Koblenz, 29 Juni 2018a. Disponível em: https://www.news4teachers.de/2018/06/endlich-wird-in-deutschland-aufgeraeumt-afdpolitiker-befluegeln-entsorgungs-fantasien-gegen-parteikritische-lehrer/. Acesso em: 31 ago. 2018. 
NEWS4TEACHERS. „Lehrer denken sozialistisch“: AfD will die Schulen auf Parteilinie bringen - und erhöht dafür den Druck („Auge um Auge“). Koblenz, 2 Juli 2018b. Disponível em: https://www.news4teachers.de/2018/07/lehrer-denken-sozialistisch-afd-will-die-schulen-aufparteilinie-bringen-und-erhoeht-dafuer-den-druck-auge-um-auge/. Acesso em: 31 ago. 2018.

PAIVA, Vera Silvia Facciolla; SILVA, Valeria Nanci. Facing negative reactions to sexuality education through a multicultural human rights framework. Reproductive Health Matters, London, v. 23, n. 46, p. 96-106, 2015.

PETÖ, Andrea. Revisionist histories, 'future memories': far-right memorialization practices in Hungary. European Politics and Society, Abingdon, v. 18, n. 1, p. 41-51, 2017.

PFANDLER, Rita. FPÖ-Homepage für "parteifreie Schule". In: MEINBEZIRK.AT. Wien, 29 März 2017. Disponível em: https://www.meinbezirk.at/oberoesterreich/c-politik/fpoehomepage-fuer\%20parteifreieschule_a2069801. Acesso em: 30 ago. 2018.

SAWICKA, Joanna; SKIBICKI, Juliusz. PiS fully engaged in re-writing Poland's history. In: POLITYKA INSIGHT. Warszawa, 31 Aug. 2017. Disponível em: https://www.politykainsight.pl/en/politics/politicsofmemory/1718010,1,pis\%20fullyengaged-inre-writing-polands-history.read. Acesso em: 22 maio 2018.

SCHLINK, Mike. Partei fühlt sich benachteiligt: AfD fordert Online-Pranger für unliebsame Lehrer. Hamburger Morgenpost, Hamburg, 29 Mai 2018. Disponível em: https://www.mopo.de/hamburg/politik/partei-fuehlt-sich-benachteiligt-afd-fordert-onlinepranger-fuer-unliebsame-lehrer-30538078. Acesso em: 11 jun. 2018.

WEAVER, Heather Lynn. What Donald Trump, Mike Pence, and Betsy DeVos won't tell you about 'School Choice'. In: AMERICAN CIVIL LIBERTIES UNION. New York, 30 Jan. 2018. Disponível em: https://www.aclu.org/blog/religious-liberty/religion-and-public-schools/whatdonald-trump-mike-pence-and-betsy-devos-wont. Acesso em: 5 set. 2018.

WEITER Aufregung um FPÖ-Meldestelle. Oberösterreichische Nachrichten, Linz, 30 März 2017. Disponível em: https://www.nachrichten.at/oberoesterreich/Weiter-Aufregung-umFPOE-Meldestelle;art4,2526338. Acesso em: 31 ago. 2018.

ZEROUALA, Faïza. Programme du FN (14): la réforme de l'éducation, une ode à un passé fantasmé. Mediapart, Paris, 23 mars 2017. Disponível em: https://www.mediapart.fr/journal/france/230317/programme-du-fn-14-la-reforme-de-Ieducation-une-ode-un-passe-fantasme?onglet=full. Acesso em: 4 set. 2018. 